\title{
Comunicação
}

[Communication]

\section{Desinserção proximal do músculo sartório na correção da luxação patelar medial graus III e IV, em cães}

[Sartorius muscle proximal release to repair grades III and IV medial patellar luxation in dogs]

\author{
E.A. Tudury ${ }^{1}$, M.L. Figueiredo ${ }^{2 *}$, B. Kemper $^{2}$, F.P. Araújo ${ }^{2}$, R. Chioratto ${ }^{1}$, N.B. Marques ${ }^{2}$, \\ T.H.T. Fernandes ${ }^{2}$ \\ ${ }^{1}$ Departamento de Medicina Veterinária - UFRPE \\ Rua Dom Manuel de Medeiros, $\mathrm{s} / \mathrm{n}$ \\ 52171-900 - Recife, PE \\ ${ }^{2}$ Aluno de pós-graduação - UFRPE - Recife, PE
}

\begin{abstract}
A luxação patelar é considerada uma das afeç̧ões mais comuns da articulação femurotibio-patelar do cão (Maria et al., 2001) e caracteriza-se pelo deslocamento medial ou lateral da patela em relação à sua posição normal no sulco troclear (Roush, 1993).
\end{abstract}

Dependendo das alterações anatômicas existentes, a luxação medial é classificada em quatro graus de acordo com o sistema de Putman (Ferguson, 1997), caracterizando-se o grau III por arqueamento lateral e rotação interna da tíbia entre 30 e $60^{\circ}$, e o grau IV por significativa rotação interna entre 60 a $90^{\circ}$ e arqueamento lateral da tíbia. A patela nesses dois graus encontra-se ectópica, mas no grau III ainda se consegue sua redução por meio de pressão manual (Vasseur, 2003).

Pesquisas sugerem que, na luxação patelar medial, o músculo sartório sofra alterações estruturais e exerça um papel importante na tensão medial, que resulta na ocorrência ou recidiva do deslocamento patelar (Wangdee et al., 2006). O sartório divide-se em duas partes: a cranial, que tem origem na crista ilíaca e na porção ventro-cranial da asa do ílio, percorre a face medial da coxa e insere-se na fáscia femoral medial, imediatamente abaixo da patela; e a caudal, que se origina na borda ventral do íleo, percorre a superfície medial do músculo vasto medial e se insere, por meio de uma aponeurose, na margem cranial da tíbia. O sartório, um dos músculos que fazem parte do mecanismo adutor da coxa, tem a função de flexionar a articulação coxofemoral e a femurotibio-patelar, contribuindo também no movimento de extensão do joelho (Evans, 1993).

O tratamento cirúrgico é necessário em luxações patelares de graus II, III e IV (Arnock e Tarvin, 1994). Geralmente, o uso de uma técnica isolada não tem bom resultado ou não é indicado para todos os graus de luxação, devendo-se associar mais de um procedimento (Schossler e Schossler, 1992). A correção cirúrgica da luxação patelar exige o alinhamento do mecanismo extensor e a estabilização da patela na tróclea femoral. Todas as anormalidades que gerem tensões anatômicas, com tendência à luxação patelar, devem ser corrigidas para evitar recidivas e insucesso cirúrgico (Maria et al., 2001).

O objetivo deste relato foi descrever uma nova técnica complementar, baseada na desinserção proximal do músculo sartório, para reduzir a tensão patelar medial em cães com luxação de graus III e IV.

Foram realizadas seis correções cirúrgicas em quatro cães de raças Toy da rotina de hospital veterinário escola, com idades variando de seis meses a quatro anos, com média de peso de $2,4 \mathrm{~kg}$. Todos os pacientes apresentavam luxação

Recebido em 9 de junho de 2009

Aceito em 22 de dezembro de 2010

*Autor para correspondência (corresponding author)

E-mail:marcellalf@hotmail.com 
medial de patela, graus III ou IV, e dois deles foram operados bilateralmente (Tab. 1). Em todos os pacientes, foram realizadas radiografias do joelho para auxiliar no planejamento cirúrgico e na avaliação de alterações degenerativas secundárias.

A abordagem à articulação do joelho foi feita segundo técnica descrita por Piermattei e Johnson (2004). Conforme cirurgias descritas por Slocum e Slocum (1998) e Piermattei et al. (2006), foram realizadas técnicas de reconstrução óssea - trocleoplastia e transposição de crista tibial - e de tecido mole imbricação lateral, suturas antirrotacionais, desmotomia medial, liberação do grupo quadríceps e transposição do tendão proximal do músculo retofemoral -, de acordo com as anormalidades musculoesqueléticas de cada paciente. A liberação do sartório foi realizada em todos os joelhos operados, na sua inserção proximal - na parte cranioventral da asa do ílio por meio de incisão cutânea, paralela à borda cranioventral da crista ilíaca, de aproximadamente 2cm, seguida de dissecação romba para identificação e posterior secção com tesoura.

Os animais foram reavaliados com 15 e 30 dias após a cirurgia, por meio de exames específicos, para se comparar a evolução após a cirurgia, de acordo com a escala funcional segundo Geels et al. (2000), a qual avalia claudicação, suporte de peso e dor em cinco graduações, sendo o Grau 1 a do animal normal e o Grau 5 a do pior sinal possível.

Em todos os pacientes, foi necessário combinar técnicas de reconstrução óssea e de tecidos moles, com o intuito de corrigir as alterações e as tensões existentes, evidenciadas na avaliação clínica pré-cirúrgica e no exame radiográfico e detectadas durante o procedimento cirúrgico. Julgamento considerável e experiência foram necessários para decidir o melhor procedimento ou combinação de procedimentos para cada caso, em particular conforme citado por Piermattei et al. ( 2006).

Tabela 1. Informações referentes ao joelho operado, ao grau de luxação e a técnicas cirúrgicas empregadas de cães submetidos à desinserção proximal do músculo sartório

\begin{tabular}{|c|c|c|c|}
\hline Paciente & Joelho & $\begin{array}{l}\text { Grau de } \\
\text { luxação }\end{array}$ & $\begin{array}{l}\text { Técnicas cirúrgicas conjuntas à desinserção proximal } \\
\text { do sartório }\end{array}$ \\
\hline \multirow[t]{2}{*}{$\begin{array}{l}\text { 1.Chiwawa, fêmea, } 2,5 \\
\text { anos, } 1,4 \mathrm{~kg}\end{array}$} & Direito & IV & $\begin{array}{l}\text { Trocleoplastia, transposição de crista tibial, sutura } \\
\text { fabelo-patelar, liberação do músculo quadríceps, } \\
\text { transposição do músculo retofemoral, desmotomia } \\
\text { medial e imbricação lateral }\end{array}$ \\
\hline & Esquerdo & IV & $\begin{array}{l}\text { Trocleoplastia, transposição de crista tibial, sutura } \\
\text { fabelo-patelar, liberação do músculo quadríceps, } \\
\text { transposição do músculo retofemoral, desmotomia } \\
\text { medial e imbricação lateral }\end{array}$ \\
\hline \multirow[t]{2}{*}{$\begin{array}{l}\text { 2. Poodle, macho, } 4 \text { anos, } \\
3,4 \mathrm{~kg}\end{array}$} & Direito & III & $\begin{array}{l}\text { Trocleoplastia, sutura antirrotacional fabelo-tibial, } \\
\text { sutura fabelo-patelar, liberação do músculo quadríceps, } \\
\text { desmotomia medial e imbricação lateral }\end{array}$ \\
\hline & Esquerdo & IV & $\begin{array}{l}\text { Trocleoplastia, transposição de crista tibial, sutura } \\
\text { fabelo-patelar, liberação do músculo quadríceps, } \\
\text { transposição do músculo retofemoral, desmotomia } \\
\text { medial e imbricação lateral }\end{array}$ \\
\hline \multirow{2}{*}{$\begin{array}{l}\text { 3. Poodle, } \\
\text { meses, 3kg }\end{array}$} & Direito & I & Tratamento conservativo \\
\hline & Esquerdo & IV & $\begin{array}{l}\text { Trocleoplastia, transposição de crista tibial, sutura } \\
\text { fabelo-patelar, liberação do músculo quadríceps, } \\
\text { desmotomia medial e imbricação lateral }\end{array}$ \\
\hline \multirow{2}{*}{$\begin{array}{l}\text { 4. Poodle, } \\
\text { meses, } 2 \mathrm{~kg}\end{array}$} & Direito & II & Não operado \\
\hline & Esquerdo & IV & $\begin{array}{l}\text { Trocleoplastia, transposição de crista tibial, sutura } \\
\text { fabelo-patelar, liberação do músculo quadríceps, } \\
\text { desmotomia medial e imbricação lateral }\end{array}$ \\
\hline
\end{tabular}


Na luxação medial, o não deslizamento e a compressão da patela no sulco troclear induzem ao arrasamento deste último (Piermattei et al., 2006), visto em todos os pacientes, tornando necessária a prática de trocleoplastia. Além disso, a tração medial exercida pelo músculo quadríceps através da patela e do ligamento patelar desvia medialmente a crista tibial, sendo indispensável, para a correção da luxação, a realização de sutura antirrotacional e, em casos mais graves, a transposição da crista. Para obter melhor alinhamento, foi necessária a liberação femoral do grupo muscular quadríceps, realizada em todos os pacientes. Em ambos os joelhos do animal 1 e no joelho esquerdo do 2, também foram necessárias a liberação do tendão proximal do músculo retofemoral, na sua inserção ilíaca, conforme técnica descrita por Slocum e Slocum (1998), e a transposição lateral visando anular sua tração para medial sobre a patela.

No joelho direito do animal 1, o primeiro a ter o músculo sartório liberado, empregaram-se todas as técnicas descritas, no entanto, mesmo após a realização destas, percebeu-se, no período transcirúrgico, ainda existir uma tração medial sobre a patela, a qual foi identificada por palpação do músculo sartório, que foi desinserido proximalmente, para desfazer a tensão. A tensão já havia sido observada em 20 animais por Wangdee et al. (2006), associada à luxação medial da patela, quando foram comparados animais com o problema e sadios. A associação desta técnica auxiliou no realinhamento do mecanismo extensor do joelho e favoreceu a recuperação do animal, observada com 15 dias. A partir desse caso, a liberação do músculo sartório foi repetida em mais cinco joelhos, verificando-se, já no transoperatório, a anulação da tração medial sobre a patela exercida pelo sartório. Todos os cães apresentaram bons resultados pós-operatórios (Fig. 1), sem sinais de recidiva, complicações ou disfunção no período de seis a 12 meses, dependendo da época da cirurgia de cada animal.

Figura 1. Avaliação ${ }^{1}$ pós-operatória dos cães segundo a escala funcional

\begin{tabular}{|c|c|c|c|c|c|c|c|c|c|c|}
\cline { 3 - 11 } \multicolumn{2}{c|}{} & \multicolumn{3}{c}{$\begin{array}{c}\text { Claudicação } \\
\text { (dia) }\end{array}$} & \multicolumn{3}{c|}{$\begin{array}{c}\text { Suporte de peso } \\
\text { (dia) }\end{array}$} & \multicolumn{3}{c|}{$\begin{array}{c}\text { Dor } \\
\text { (dia) }\end{array}$} \\
\hline Paciente & Joelho & 0 & 15 & 30 & 0 & 15 & 30 & 0 & 15 & 30 \\
\hline \multirow{2}{*}{$\mathrm{n} .1$} & Direito & 5 & 2 & 1 & 5 & 2 & 1 & 3 & 2 & 1 \\
\cline { 2 - 12 } & Esquerdo & 5 & 2 & 1 & 5 & 2 & 1 & 4 & 2 & 1 \\
\hline n. 2 & Direito & 4 & 2 & 1 & 4 & 3 & 1 & 3 & 2 & 1 \\
\cline { 2 - 12 } & Esquerdo & 5 & 2 & 1 & 5 & 2 & 1 & 3 & 2 & 1 \\
\hline n. 3 & Esquerdo & 4 & 2 & 2 & 3 & 2 & 2 & 2 & 2 & 1 \\
\hline n. 4 & Esquerdo & 4 & 2 & 1 & 4 & 2 & 1 & 2 & 2 & 1 \\
\hline
\end{tabular}

1: dias após a cirurgia; 2: Geels et al. (2000).

Apesar de Wangdee et al. (2006) citar que a alteração do músculo sartório é acompanhada de hipertrofia de fibras individuais, diferentes tamanhos de fibras musculares, degeneração de Zenker, infiltração com fibras de colágeno e espessamento da bainha conjuntiva, não foi realizado exame por biópsia destes pacientes, por tratar-se de casos clínicos em que se tinha o objetivo de causar o menor trauma possível, mas a tensão existente no músculo, mesmo já tendo sido efetuados todos os outros procedimentos cirúrgicos de liberação da patela, era palpável e correspondia às observações clínicas citadas por esses autores.

Acredita-se que, nos cães em que o músculo sartório se encontra encurtado, sua desinserção proximal é necessária e eficaz como técnica complementar para reduzir a tensão medial e recidiva na luxação patelar medial dos graus III e IV.

Palavras-chave: cão, cirurgia, joelho 


\begin{abstract}
Six surgical corrections were performed with techniques of bone and soft tissue reconstruction, according to the individual presentation of each patient, in four Toy breed dogs, which had grades III and IV luxation, two of them bilaterally operated. During the recovery excessive medial tension associated to the Sartorius muscle was detected, which motivated its release at the iliac insertion. The animals had a functional recovery of the limb after 15 days, and complications or loss of function related to the release of the Sartorius muscle were not observed even after six months. It is believed that the proximal disinsertion of this muscle can be necessary and effective in some patients as a complementary technique to release medial tension in dogs with grades III and IV medial patellar luxation.
\end{abstract}

Keywords: dog, surgery, stifle joint

\section{REFERÊNCIAS BIBLIOGRÁFICAS}

ARNOCK, S.P.; TARVIN, G.B. Reparo cirúrgico das luxações e fraturas patelares. In: BOJRAB, M.J. (Ed). Técnicas atuais em cirurgia de pequenos animais. 3.ed. São Paulo: Roca, 1994. p.275-279.

EVANS, H. E. Arthrology. In:_. Miller's anatomy of the dog. 3.ed. Philadelphia: Saunders, 1993. p.219-257.

FERGUSON, J. Patellar luxation in the dog and cat. Practice, v.19, p.174-184, 1997.

GEELS, J.J.; ROUSH J.K.; HOSKINSON J.J. et al. Evaluation of intracapsular technique for the treatment of cranial cruciate ligament rupture. Vet. Comp. Orthop. Traumatol., v.13, p.197-203, 2000.

MARIA, P.P.; PADILHA-FILHO, J.G.; ALMEIDA, T.L. Luxação medial de patela em cães - revisão. Clin. Vet., v.6, p.25-32, 2001.

PIERMATTEI, D.L.; FLO, G.L.; DECAMP, C.L. The stifle joint. In: _. Brinker, Piermattei, and Flo's handbook os small animal orthopedics and fracture repair. 4.ed. Saint Louis: Saunders, 2006. p.562-632.
PIERMATTEI, D.L.; JOHNSON, K.A. (Eds). An atlas of surgical approaches to the bones and joints of the dog and cat. 4.ed. Philadelphia: Saunders, 2004. 400p.

ROUSH, J.K. Canine patellar luxation. Vet. Clin. N. Am.: Small Anim. Pract., v.23, p.855-868, 1993.

SCHOSSLER, J.E.;SCHOSSLER, D.R. Correção cirúrgica de luxação medial de patela em cão. Cães gatos, n.36, p.4-7, 1992.

SLOCUM, B.; SLOCUM, T.D. Knee. In: BOJRAB, M.J.; ELLISON, G.W.; SLOCUM, B. (Eds). Current techniques in amall animal surgery. 4.ed. Baltimore: Williams \& Wilkins, 1998. p.1187-1244.

VASSEUR, P.B. Stifle joint. In: SLATTER, D. (Ed). Textbook of small animal surgery. 3.ed. Philadelphia: Saunders, 2003. p.2090-2133

WANGDEE, C.; CHUTHATEP, S.; SOONTORNVIPART, K. et al. The structural study of the sartorius of .medial patellar luxated dogs. In: ANNUAL CONGRESS OF VETERINARY SCIENCE, 2006, Chulalongkorn. Proceedings... Chulalongkorn, 2006. 